\title{
MUC1 and MUC13 differentially regulate epithelial inflammation in response to inflammatory and infectious stimuli
}

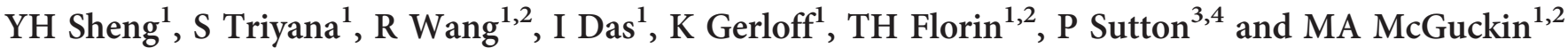

The MUC1 cell-surface mucin is highly expressed on the gastric mucosal surface, while MUC13 is highly expressed on the intestinal mucosal surface. Polymorphisms in both MUC1 and MUC13 have been linked to inflammatory bowel diseases. MUC1 can act as a decoy molecule on the apical cell surface of epithelial cells and thereby limit bacterial adherence, infection, and inflammation. In this study, we examined whether and how MUC1 and MUC13 modulate infectious and inflammatory signaling. Using gastrointestinal tissue from Muc1- or Muc13-deficient mice in ex vivo culture, MUC1 small interfering RNA (siRNA) silencing in MKN7 gastric epithelial cells, and MUC13 siRNA silencing in LS513 intestinal epithelial cells, we showed that loss of MUC1 increased chemokine secretion, whereas loss of MUC13 decreased chemokine secretion in response to tumor necrosis factor- $\alpha$. Anti-inflammatory activity of MUC1 and proinflammatory activity of MUC13 were also seen after exposure to pathogens, NOD1 (nucleotide-binding oligomerisation domain-containing protein-1), and Toll-like receptor ligands. MUC1 and MUC13 both regulate chemokine secretion in gastrointestinal epithelial cells through a nuclear factor- $\mathrm{kB}$-dependent pathway, although MUC13 modulation could also involve other pathways. Our studies demonstrate that MUC1 and MUC13 are important components of gastrointestinal homeostasis and that disruption or inappropriate expression of these mucins could predispose to infectious and inflammatory disease and inflammation-induced cancer.

\section{INTRODUCTION}

MUC1 and MUC13 are transmembrane mucin glycoproteins that are expressed on the apical surface of mucosal epithelial cells, as well as the surface of some hematopoietic cells. ${ }^{1}$ Because of their long filamentous nature, cell surface mucins are likely to be the first point of direct contact between host tissue and organisms that penetrate the secreted mucus layer. ${ }^{1}$

There is considerable evidence that cell surface mucins provide a barrier to potential pathogens and modulate responses to inflammatory cytokines. ${ }^{1}$ Deficiency in Mucl protects mice from dextran sulfate sodium (DSS)-induced colitis, ${ }^{2}$ but predisposes mice to gastrointestinal infection. ${ }^{3,4}$ Conversely, Muc13 protects against intestinal epithelial damage and inflammation induced by DSS, ${ }^{5}$ but the effect of deficiency of Muc13 on gastrointestinal infection is not known.
Inflammatory diseases of the gastrointestinal tract, ulcerative colitis and Crohn's disease (together known as inflammatory bowel disease (IBD)), and gastrointestinal infections, remain a substantial cause of morbidity and major contributors to health care costs in the developed and developing world. ${ }^{6}$ Polymorphisms in both the MUC1 and MUC13 genes have been linked to IBD. ${ }^{7,8}$ Additionally, variant alleles of $M U C 1$ and MUC13 have been implicated in Helicobacter pylori infection in humans, ${ }^{9,10}$ and in enterotoxigenic E. coli in pigs, ${ }^{11}$ respectively.

The relative expression of gastrointestinal cell surface mucins varies between different regions of the tract and between different cell types within each region, ${ }^{1}$ where they can be rapidly adjusted to changes in the environment to limit microbial infection and modulate the activation of inflammatory responses at the interface with environment. ${ }^{1}$ For example,

\footnotetext{
${ }^{1}$ Immunity, Infection and Inflammation Program, Mater Medical Research Institute, The University of Queensland, Queensland, Australia. ${ }^{2}$ Mater Health Services, The University of Queensland, South Brisbane, Queensland, Australia. ${ }^{3}$ Mucosal Immunology, Murdoch Children's Research Institute, Royal Children's Hospital, Parkville, Melbourne, Australia and ${ }^{4}$ School of Veterinary Science, University of Melbourne, Parkville, Melbourne, Australia. Correspondence: MA McGuckin (mmcguckin@mmri.mater.org.au)
} 
in health, MUC1 is the predominant cell surface mucin in the stomach, ${ }^{12}$ whereas MUC3, MUC4, MUC12, MUC13, and MUC17 are the major cell surface mucins in the intestine, with less MUC1 present. ${ }^{13}$ However, Muc1/MUC1 is upregulated in the inflamed intestine induced by Campylobacter jejuni and C. rodentium infection in mice ${ }^{3,14}$ and in ulcerative colitis in humans, ${ }^{15}$ whereas Muc13/MUC13 is upregulated in the inflamed stomach in $H$. pylori-infected mice (our unpublished data) and humans. ${ }^{16}$ Hence, MUC1 is upregulated in the intestine, while MUC13 is upregulated in the stomach by infection and inflammation. The fact that their expression changes during infection and inflammation suggests they are likely to make functional contributions to the mucosal barrier.

MUC1, the most extensively studied membrane-associated mucin, has been shown to modulate Toll-like receptor (TLR) signaling. ${ }^{17}$ MUC1 is constantly internalized by clathrinmediated endocytosis and recycled back to the cell surface, thus imparting capacity to carry cargo into the cell. ${ }^{18}$ Importantly, this places MUC1 in endosomes occupied by the intracellular TLRs, including TLR3, 4, 7, 8, and 9, and TLR4 following its internalization from the cell surface. Interaction with bacteria can induce phosphorylation of MUC1 in vitro ${ }^{19}$ and MUC1 has been shown to dampen TLR signaling. ${ }^{17,20}$ Furthermore, MUC1 has been proposed to suppress inflammation by inhibiting nuclear factor (NF)- $\kappa \mathrm{B}$ activity in response to H. pylori infection in the AGS (Human Stomach Adenocarcinoma cell line; CRL-1739, ATCC, Manassas, VA) gastric cancer cell line. ${ }^{21}$ On the other hand, MUC1 was shown to drive constitutive NF- $\kappa$ B activation in MCF-10A and ZR-75-1 breast cancer cells by binding directly to I kappaB kinase $\beta$ (IKK $\beta)$ and I kappaB kinase $\gamma(\mathrm{IKK} \gamma)$ resulting in phosphorylation and degradation of I kappaB $\alpha(\mathrm{I} \kappa \mathrm{Ba}),{ }^{22,23}$ suggesting that the role of MUC1 in inflammation is highly complex.

We demonstrated previously that Muc13 protects against intestinal inflammation induced by DSS toxin, ${ }^{5}$ but empirical in vivo and in vitro studies examining a role of MUC13 in modulation of inflammatory signaling are lacking. In this study, we show that in gastrointestinal epithelial cells following exposure to cytokines, pathogens, or microbial molecules, MUC1 and MUC13 have opposing influences on inflammatory signaling.

\section{RESULTS}

MUC1 and MUC13 differentially regulate IL-8 expression in response to tumor necrosis factor- $\alpha$ (TNF- $\alpha$ )

To compare the relative effects of Mucl and Muc13 on the inflammatory response, we first used gastric tissue biopsies from Mucl-deficient mice (as Mucl is highly expressed in the stomach) and intestinal tissue biopsies from Muc13-deficient mice (as Muc13 is highly expressed in the intestine). We compared the ability of ex vivo-cultured tissue explants from $\mathrm{Mucl}^{-/-}$or $\mathrm{Muc13^{-/- }}$ mice and their respective wild-type counterparts to mount proinflammatory responses to TNF- $\alpha$. The production of the chemokine macrophage inflammatory protein-2 $\alpha$ (MIP-2 $\alpha$; Cxcl2), which has biological activities in mice analogous to those of human interleukin (IL)- $8,{ }^{24,25}$ was used to measure inflammatory signaling. In response to TNF- $\alpha$ stimulation, secretion of MIP- $2 \alpha$ was significantly higher from the $\mathrm{Mucl}^{-/-}$gastric tissue than wild-type tissue from $1.5 \mathrm{~h}$ up to $24 \mathrm{~h}$, whereas production of MIP- $2 \alpha$ was significantly lower from the $M u c 13^{-/-}$intestinal tissue than wild-type tissue from $6 \mathrm{~h}$ up to $24 \mathrm{~h}$ (Figure 1). These data indicated that Muc1 and Muc13 have opposing effects on the response of the gastrointestinal epithelium to inflammatory challenge.

Although Muc1 has very low expression in the epithelium of the intestine, it could be expressed in lamina propria leukocytes. We therefore investigated MIP- $2 \alpha$ secretion from ex vivocultured intestinal tissue explants from $\mathrm{Mucl}^{-/-}$and wild-type mice. There was no difference in production of MIP- $2 \alpha$ between $M u c 1^{-/-}$intestinal tissue and wild-type intestinal tissue in response to TNF- $\alpha$ (Supplementary Figure S1 online).

Given mixed cell types are present in gastrointestinal biopsies, MKN7 human gastric epithelial cells and LS513 colonic epithelial cells were used to confirm the ex vivo results in an in vitro epithelial cell monoculture system. MKN7 cells (which express high levels of MUC1 and barely detectable levels of MUC13) and LS513 cells (which express high levels of MUC13 and small amounts of MUC1) were transfected with MUC1 or MUC13 small interfering RNA (siRNA), respectively, for $48 \mathrm{~h}$ and then treated with $10 \mathrm{ng} \mathrm{ml}^{-1}$ of TNF- $\alpha$ for $24 \mathrm{~h}$ and IL- 8 levels in culture media were measured by ELISA. Two sets of siRNAs, specific for distinct regions of the MUC1 or MUC13 mRNAs, were utilized to control for potential off target effects. Each set of MUC1 siRNA or MUC13 siRNA exhibited $>85 \%$ reduction in MUC1 and MUC13 protein levels $72 \mathrm{~h}$ post-transfection, respectively, compared with cells transfected with control siRNA (Figure 2a,b). Knockdown of MUC1 in MKN7 cells increased IL-8 secretion, whereas knockdown of MUC13 in LS513 cells decreased IL-8 secretion compared with control siRNA after $24 \mathrm{~h}$ TNF- $\alpha$ treatment (Figure $2 \mathbf{c}, \mathbf{d}$ ). Because similar results were observed with the different siRNA for each gene (Figure $\mathbf{2} \mathbf{c}, \mathbf{d}$ ), one siRNA was used in all
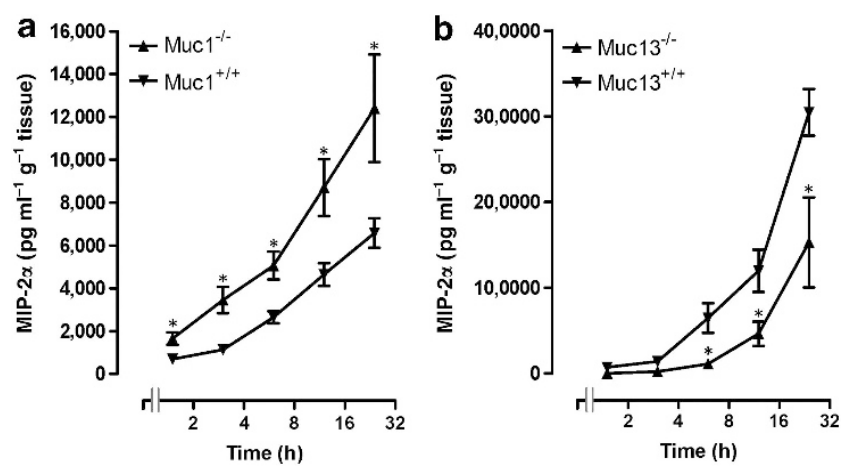

Figure 1 Altered responsiveness of gastrointestinal tissue explants from Muc1 $^{-1-}$ and Muc13 $^{-/-}$mice to tumor necrosis factor- $\alpha$ (TNF- $\alpha$ ) stimulation in ex vivo culture. (a) Gastric explants from Muc1 ${ }^{-1-}$ and wildtype (WT) mice were treated with TNF- $\alpha\left(10 \mathrm{ng} \mathrm{ml}^{-1}\right)$ and secreted macrophage inflammatory protein-2 $\alpha$ (MIP-2 $\alpha$; Cxcl2) was measured by enzyme-linked immunosorbent assay over $24 \mathrm{~h}$. (b) Intestinal explants

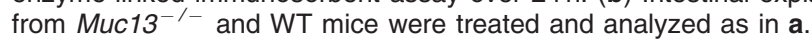
Statistics: mean \pm s.e.m.; $n \geqslant 6$; Mann-Whitney $U$-test WT vs. Muc1 ${ }^{-1-}$ stomach explants (a) or WT vs. Muc13 ${ }^{-/-}$colon explants (b), ${ }^{\star} P<0.05$. 




c MKN7

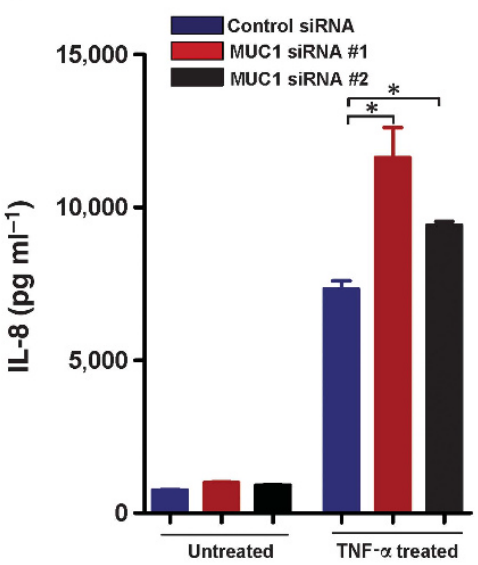

e

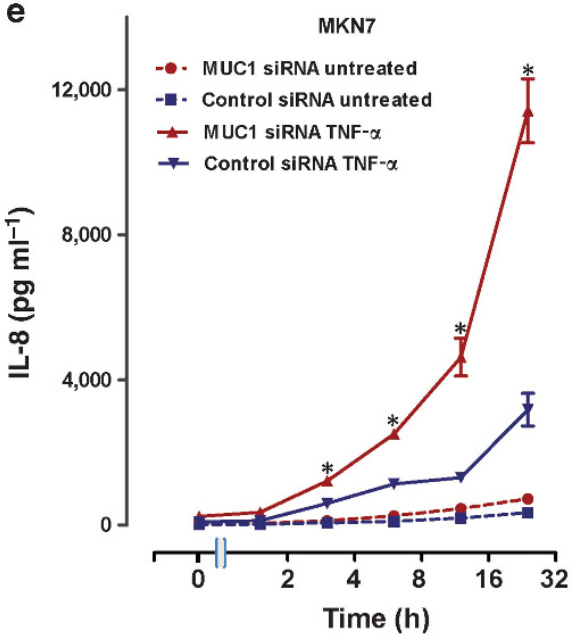

b

d
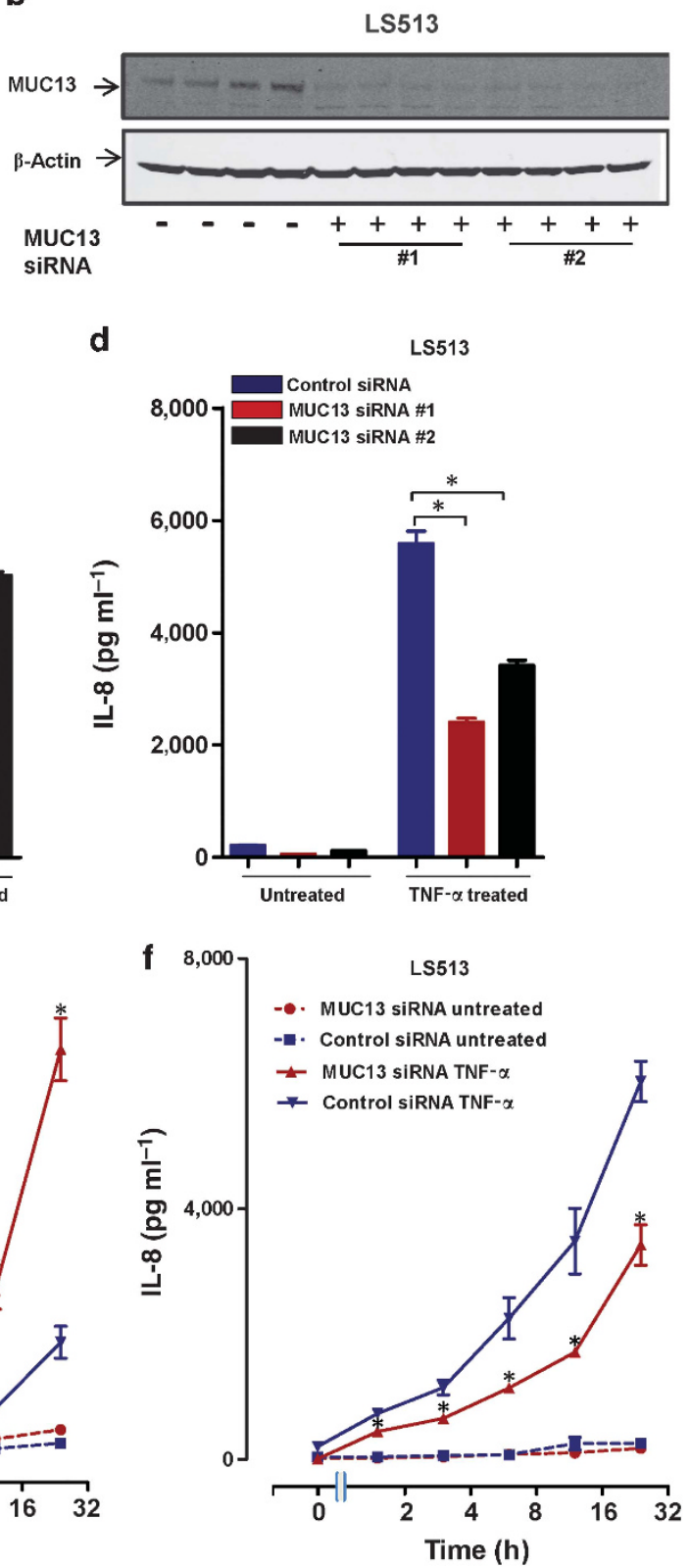

Figure 2 MUC1 and MUC13 differentially regulate interleukin (IL)-8 secretion in response to inflammatory stimuli in cultured gastric and intestinal epithelial cells. (a) MKN7 cells reduced MUC1 expression on the cell surface after $48 \mathrm{~h}$ transfection with two distinct MUC1 small interfering RNA (siRNA) vs. control siRNA as determined by flow cytometry. (b) Knockdown of MUC13 in LS513 cells $48 \mathrm{~h}$ after transfection with control siRNA or two distinct MUC13 siRNA assessed by western blotting. (c) MKN7 cells were transfected with MUC1 or control siRNA for 48h, treated with tumor necrosis factor- $\alpha$ (TNF- $\alpha ; 10 \mathrm{ng} \mathrm{ml}^{-1}$ ) for $24 \mathrm{~h}$, and IL-8 levels in culture media measured by enzyme-linked immunosorbent assay (ELISA). (d) LS513 cells were transfected with MUC13 or control siRNA for $48 \mathrm{~h}$, treated with TNF- $\alpha$ (10 ng ml ${ }^{-1}$ ) for $24 \mathrm{~h}$, and IL-8 measured by ELISA. (e) MKN7 cells treated as in c with IL-8 levels in culture media measured over $24 \mathrm{~h}$. (f) LS513 cells were treated as in d with IL-8 levels measured over $24 \mathrm{~h}$. $(\mathbf{a}-\mathbf{f})$ Each group contained four independent replicates, representative of three separate experiments. Statistics $(\mathbf{c}-\mathbf{f})$ : mean $\pm \mathrm{s} . \mathrm{e} . \mathrm{m}$.; $n \geqslant 4$; Mann-Whitney U-test MUC1 siRNA or MUC13 siRNA vs. control siRNA, ${ }^{\star} P<0.05$.

subsequent experiments, which confirmed that negative regulation of IL- 8 production by MUC1 and positive regulation of IL- 8 by MUC13 occurred from $3 \mathrm{~h}$ up to $24 \mathrm{~h}$ after exposure to TNF- $\alpha$ (Figure 2e,f).

Because MUC1 and MUC13 can be expressed in the same cell, we investigated whether there is compensation in MKN7 cells when MUC1 was knocked down, or in LS513 cells and another human intestinal epithelial cell line, LIM2463, when
MUC13 was knocked down, by measuring the mRNA expression of MUC1 and MUC13 in silenced cells before and after $24 \mathrm{~h}$ TNF- $\alpha$ treatment. Knockdown of MUC1 in MKN7 cells did not increase expression of MUC13 (Figure 3a). However, there was a $~ 50 \%$ increase in expression of MUC1 in LS513 cells but no change in LIM2463 cells when MUC13 was silenced (Figure 3b). We therefore measured IL-8 secretion when both MUC1 and MUC13 were silenced together in LS513 
a

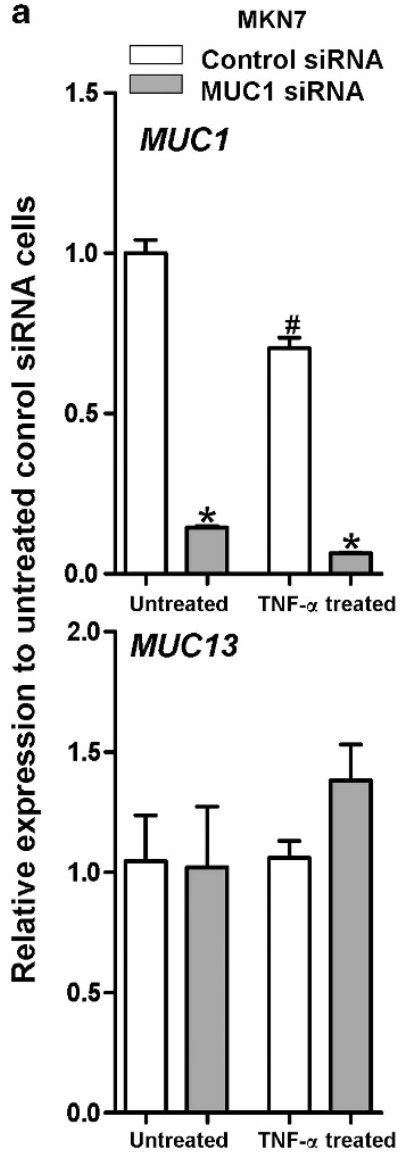

b

LS513

$\square$ Control siRNA MUC13 SIRNA

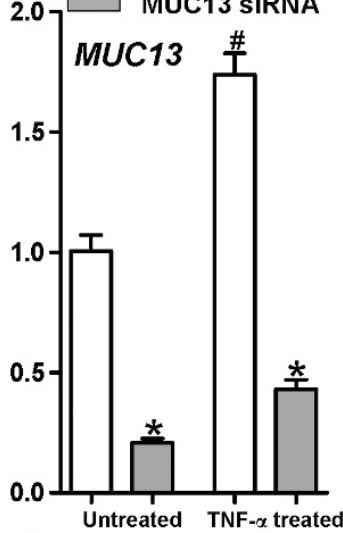

$\left.{ }^{2.5}\right]$ MUC1

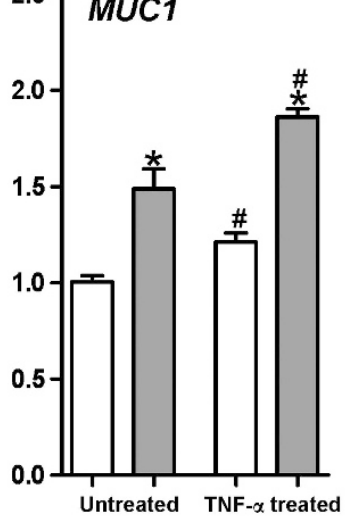

LIM2463

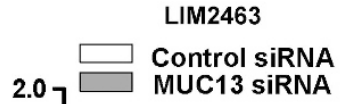

MUC13 siRNA

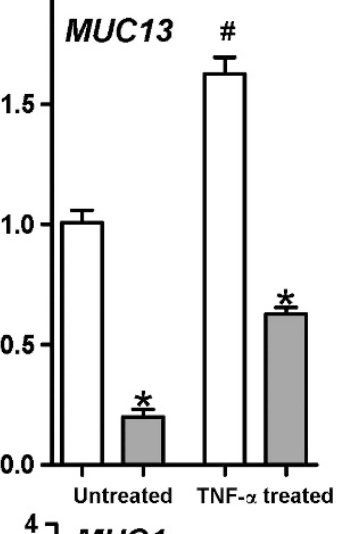

$\left.{ }^{4}\right]$ MUC1

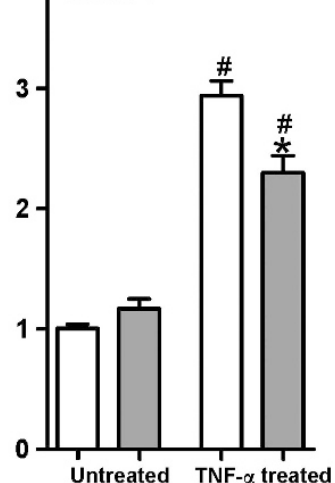

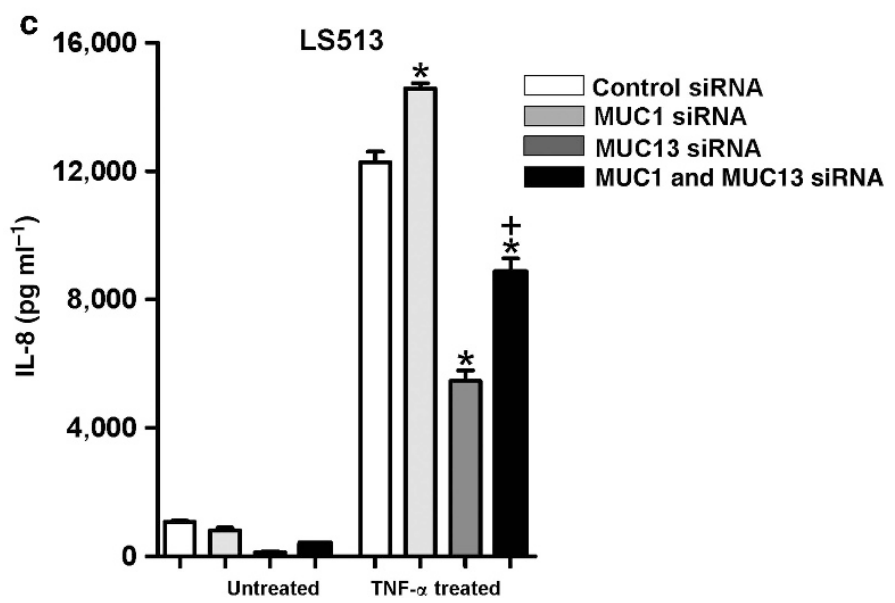

Figure 3 Expression of MUC1 and MUC13 genes in MKN7, LS513, and LIM2463 cells. (a) MKN7 cells were transfected with MUC1 or control small interfering RNA (siRNA) for $48 \mathrm{~h}$, then stimulated with tumor necrosis factor- $\alpha$ (TNF- $\alpha ; 10 \mathrm{ng} \mathrm{ml}^{-1}$ ). MUC1 and MUC13 expression levels were measured by real-time PCR. (b) LS513 and LIM2463 cells were transfected with MUC13 or control siRNA for $48 \mathrm{~h}$, then stimulated with TNF- $\alpha$ (10 $\mathrm{ng} \mathrm{ml}^{-1}$ ). MUC1 and MUC13 expression levels were measured by real-time PCR. (c) LS513 cells were transfected with MUC1 and MUC13, either individually or together, or control siRNA for $48 \mathrm{~h}$, treated with TNF- $\alpha\left(10 \mathrm{ng} \mathrm{ml}^{-1}\right)$ for $24 \mathrm{~h}$, and interleukin (IL)-8 measured by enzyme-linked immunosorbent assay. For $(\mathbf{a}-\mathbf{c})$, each group contained four independent replicates in an experiment representative of three separate experiments. Statistics: mean \pm s.e.m.; $n \geqslant 4$; Mann-Whitney $U$-test; ${ }^{*} P<0.05$ for control siRNA vs. mucin siRNA for each condition; ${ }^{\#} P<0.05$ for TNF- $\alpha$ vs. control for each siRNA; ${ }^{+} P<0.05$ MUC1 plus MUC13 siRNA vs. MUC13 siRNA.

cells. When MUC1 was silenced there was a $\sim 20 \%$ increase in TNF- $\alpha$-induced IL- 8 secretion, and when MUC13 was silenced there was a $\sim 55 \%$ decrease in IL-8 secretion, consistent with the previous experiments and the relative abundance of MUC1 and MUC13. When both mucins were silenced IL-8 production was intermediate ( $\sim 27 \%$ decrease vs. control; Figure $3 c)$. This experiment shows that MUC1 and MUC13 have competing influences on inflammatory activation when expressed together 
and the relative abundance will determine which mucin has the dominant effect.

MUC1 suppresses NF-кB p65 activity through inhibition of IкB $\alpha$ phosphorylation and degradation whereas MUC13 promotes NF-кB p65 activation by inducing phosphorylation and degradation of $1 \mathrm{\kappa} B \alpha$

As NF- $\mathrm{KB}$ is the main driver of IL-8 transcription in gastrointestinal epithelial cells, we therefore investigated whether the modulation of IL- 8 production by MUC1 and MUC13 was due to altered NF- $\kappa B$ signaling. TNF- $\alpha$ driven NF$\kappa \mathrm{B}$ activation in gastric and intestinal cells, with either normal or reduced mucin expression, was examined by using an AlphaScreen SureFire Assay and western blotting. As shown in Figure 4a, knockdown of MUC1 with siRNA in MKN7 cells significantly increased NF- $\mathrm{KB}$ p 65 phosphorylation compared with cells transfected with the control siRNA at 15 and $60 \mathrm{~min}$ post-treatment with TNF- $\alpha$. Conversely, knock down of MUC13 in LS513 cells reduced NF- $\kappa \mathrm{B}$ p65 phosphorylation between 15 and $60 \mathrm{~min}$ post-treatment with TNF- $\alpha$ (Figure 4b).

Phosphorylation of $I \kappa B \alpha$ is essential for induction of NF- $\kappa B$ activity in the classical pathway as phosphorylated IкB $\alpha$ is targeted for ubiquitination and dissociation from NF- $\kappa \mathrm{B}$, which leads to the activated transcription factor translocating into nucleus. ${ }^{26}$ We therefore investigated whether the MUC1 or MUC13 regulation of the NF- $\kappa B$ activity is mediated via modulation of phosphorylation of $\mathrm{I} \kappa \mathrm{B} \alpha$. Silencing of $M U C 1$ in MKN7 cells increased phosphorylation of I $\mathrm{I} B \alpha$, degradation of total $\mathrm{I} \kappa \mathrm{B} \alpha$, and nuclear targeting of NF- $\kappa \mathrm{B}$ p 65 in the response to TNF- $\alpha$ stimulation compared with control siRNA-transfected cells (Figure 5a,d). By contrast, knockdown of MUC13 in LS513 cells decreased phosphorylation and degradation of $\mathrm{I} \kappa \mathrm{B} \alpha$, and nuclear targeting of NF- $\kappa \mathrm{B}$ p 65 in the response to TNF- $\alpha$ stimulation, compared with control siRNA-transfected cells (Figure 5b,d). This was further confirmed in LIM2463 cells (Figure $\mathbf{5 c , d}$ ).

Next, we used an inhibitor of I $\mathrm{K} \mathrm{B} \alpha$ phosphorylation, Bay 117085 , to determine whether modulation of IL- 8 production by
MUC1 or MUC13 is mainly attributable to altered phosphorylation of IkBa. Pretreatment of MKN7 cells with Bay 11-7085 completely blocked TNF- $\alpha$-induced IL- 8 production (Figure 6a). In TNF- $\alpha$-stimulated MKN7 cells, knockdown of MUC1 did not result in increased IL-8 production when the $\mathrm{NF}-\kappa \mathrm{B}$ inhibitor was present (Figure 6a), suggesting that MUC1 modulates IL- 8 by suppressing TNF- $\alpha$-induced NF- $\kappa B$ activity. By contrast, pretreatment of LIM2463 or LS513 cells with Bay 11-7085 only partially blocked TNF- $\alpha$-stimulated IL-8 induction in these MUC13-expressing cells (Figure $6 \mathbf{b}$ ) and almost completely blocked TNF- $\alpha$-stimulated IL-8 production when MUC13 was silenced (Figure 6b). Taken together, these experiments suggest that MUC13 modulation of IL-8 production is partially attributable to phosphorylation of I $\mathrm{B} \alpha$ but can also occur via an I $\mathrm{B} \alpha$-independent pathway.

MUC1 is known to interact with the ErbB family of growth factor receptors and MUC13 contains epidermal growth factor (EGF)-like domains, which could interact with these receptors. Therefore, we treated cells with the anti-EGF receptor (ErbB-1) antibody, cetuximab, and the anti-ErbB-2 antibody, trastuzumab, before TNF- $\alpha$ treatment in cells with and without MUC13 knockdown. These antibodies had no effect on IL-8 production on their own, but both antibodies inhibited IL-8 production in response to TNF- $\alpha$. Cells with silenced MUC13 produced less IL-8 regardless of the presence of antibodies, suggesting that MUC13 modulation of IL-8 production is unlikely to involve modulation of ErbB-1 or ErbB-2 signaling (Supplementary Figure S2 online).

\section{MUC1 and MUC13 differentially regulate IL-8 expression in response to infectious stimuli}

In addition to the ability of MUC1 and MUC13 to regulate IL-8 expression in response to TNF- $\alpha$, we examined whether these cell surface mucins modulate the response of gastrointestinal epithelial cells to live gastrointestinal bacteria. MKN7 gastric epithelial cells were co-cultured with the gastric pathogen H. pylori and LS513 intestinal epithelial cells were co-cultured with the intestinal pathogen C. jejuni under microaerophilic
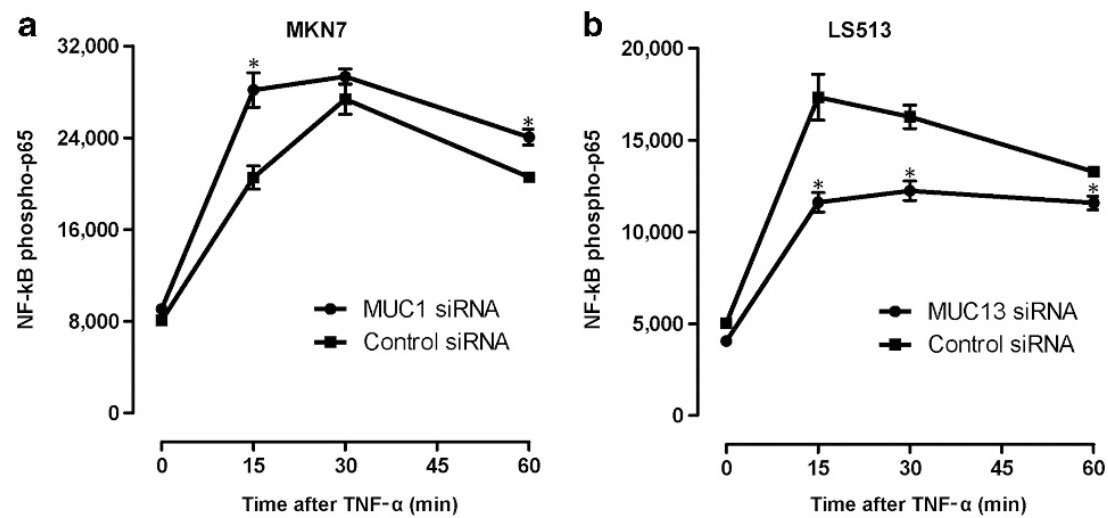

Figure 4 MUC1 inhibits, whereas MUC13 promotes tumor necrosis factor- $\alpha$ (TNF- $\alpha$ )-induced nuclear factor (NF)-kB activation. (a) MKN7 cells were transfected with MUC1 or control small interfering RNA (siRNA) for $48 \mathrm{~h}$ and treated with TNF- $\alpha\left(10 \mathrm{ng} \mathrm{ml}^{-1}\right)$ for the indicated times. Phosphorylation of NF-кB p65 Ser536 was measured by AlphaScreen SureFire Assay. (b) LS513 cells were transfected with MUC13 or control siRNA for 48 h and treated and assayed as in a. Statistics (a, b): mean \pm s.e.m.; $n \geqslant 4$; Mann-Whitney $U$-test MUC1 siRNA (a) or MUC13 siRNA (b) vs. control siRNA, ${ }^{\star} P<0.05$. 

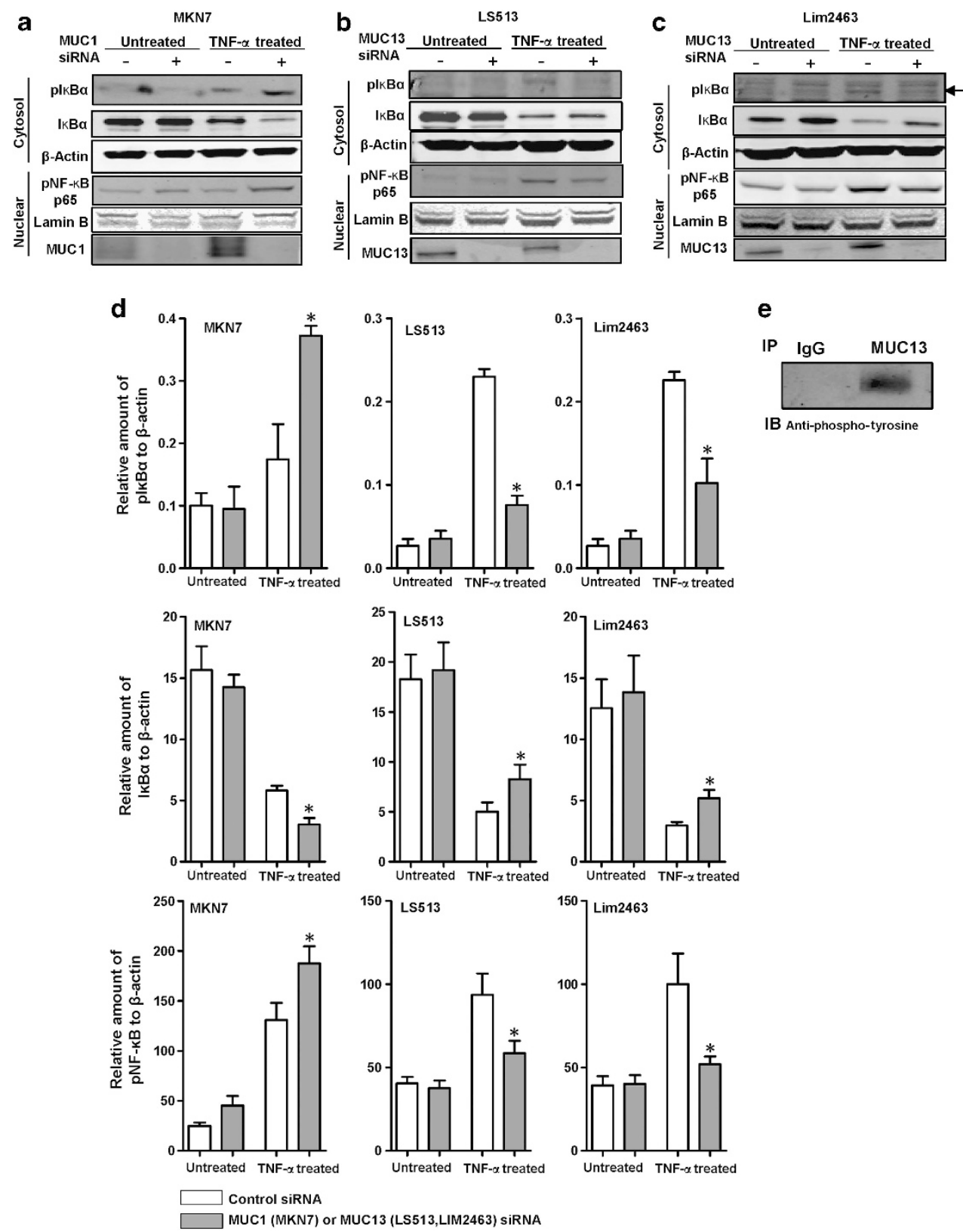

Figure 5 Silencing of MUC1 promotes translocation of p65 to the nucleus by inducing phosphorylation and degradation of IkB $\alpha$ in response to tumor necrosis factor- $\alpha$ (TNF- $\alpha$ ), whereas MUC13 silencing has opposite effects. (a) MKN7 cells were transfected with MUC1 or control small interfering RNA (siRNA) for $48 \mathrm{~h}$ and treated with TNF- $\alpha\left(10 \mathrm{ng} \mathrm{ml}^{-1}\right)$ for $15 \mathrm{~min}$. Cytosolic fractions and nuclear fraction were immunoblotted with indicated antibodies. (b) LS513 or (c) LIM2463 cells were transfected with MUC13 or control siRNA and treated and assessed as in a. (d) Densitometric analysis of four replicates of the western blots from a-c. Protein expression was normalized to the house-keeping gene $\beta$-actin. Statistics (d): mean \pm s.e.m.; Mann-Whitney U-test MUC1 siRNA (a) or MUC13 siRNA (b, c) vs. control siRNA, ${ }^{*} P<0.05$. (e) Lysate from LS513 cell was subjected to immunoprecipitation (IP) with a control immunoglobulin G (IgG) or anti-MUC13 antibody. The precipitates were immunoblotted (IB) with anti phospho-tyrosine mAb.

conditions. MKN7 and LS513 cells were, respectively, transfected with MUC1- or MUC13-targeting siRNA for $48 \mathrm{~h}$, and the cells were co-cultured with live bacteria for a further $24 \mathrm{~h}$. Knockdown of MUC1 in MKN7 cells resulted in increased production of IL-8 in response to $H$. pylori compared with control siRNA, whereas knockdown of MUC13 in LS513 cells resulted in decreased IL- 8 in response to $C$. jejuni compared with control siRNA (Figure 7), reproducing the modification of IL-8 production seen with TNF- $\alpha$. Highlighting the significance of MUC13, after exposure to C. jejuni MUC13deficient cells produced no more IL-8 than MUC13-expressing cells not exposed to the bacteria.

\section{MUC1 inhibits and MUC13 enhances epithelial cell inflammatory signaling in response to nucleotide-binding oligomerisation domain (NOD) and TLR ligands}

Next, we extended these findings to explore the interactions of MUC1 and MUC13 with NOD and TLR ligands. MKN7 cells in 

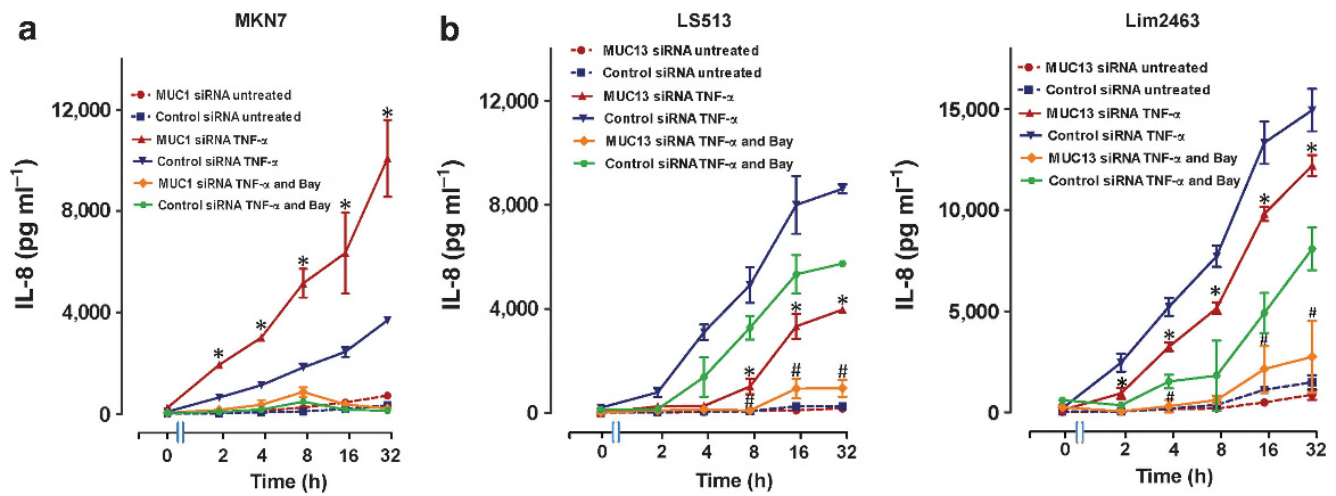

Figure 6 The modulation of interleukin (IL)-8 production by MUC1 and MUC13 is attributable to altered phosphorylation of IkB $\alpha$. (a) MKN7 cells were transfected with MUC1 or control small interfering RNA (siRNA) for $48 \mathrm{~h}$ and pretreated with $20 \mu \mathrm{m}$ of the nuclear factor (NF)-KB inhibitor Bay $11-7085$ (Bay) for $1 \mathrm{~h}$, then cells were stimulated with tumor necrosis factor- $\alpha$ (TNF- $\alpha ; 10 \mathrm{ng} \mathrm{ml}^{-1}$ ) and IL-8 levels in culture media were measured by enzyme-linked immunosorbent assayat the indicated times. (b) LS513 and LIM2463 cells were transfected with MUC13 or control siRNA for $48 \mathrm{~h}$ and treated and assessed as in $\mathbf{a}$. $(\mathbf{a}, \mathbf{b})$ : Each group contained four independent replicates, representative of three separate experiments. Statistics: mean \pm s.e.m.; $n \geqslant 4$; Mann-Whitney $U$-test MUC1 siRNA (a) or MUC13 siRNA vs. control siRNA (b), ${ }^{*} P<0.05$ for treated with TNF- $\alpha,{ }^{\#} P<0.05$ for treated with TNF- $\alpha$ plus Bay 11-7085.

a

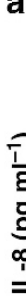

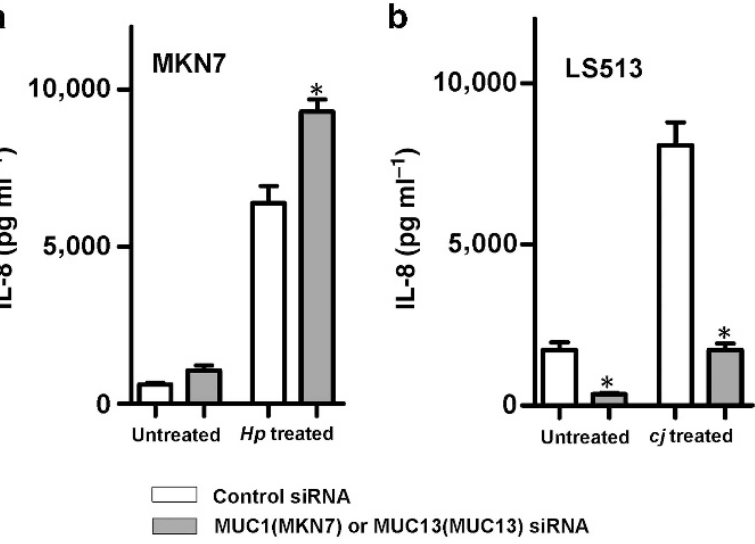

Figure 7 MUC1 and MUC13 differentially regulate intereukin (IL)-8 production by gastrointestinal cells in response to pathogenic bacteria. (a) MKN7 cells were transfected with MUC1 or control small interfering RNA (siRNA) for $48 \mathrm{~h}$ and co-cultured with Helicobacter pylori $(\mathrm{Hp})$ for $24 \mathrm{~h}$ and IL-8 levels in culture media measured by enzyme-linked immunosorbent assay (ELISA). (b) LS513 cells were transfected with MUC13 or control siRNA for $48 \mathrm{~h}$ and co-cultured with Campylobacter jejuni $(C J)$ for $24 \mathrm{~h}$ and IL-8 levels in culture media measured by ELISA. $(\mathbf{a}, \mathbf{b})$ Each group contained four independent replicates, representative of three separate experiments. Statistics: mean \pm s.e.m.; $n \geqslant 4$; MannWhitney $U$-test; ${ }^{*} P<0.05$ for MUC1 siRNA (a) or MUC13 siRNA (b) vs. control siRNA.

which MUC1 had been knocked down, or LS513 and LIM2463 cells in which MUC13 had been knocked down, were treated with NOD1 ligand and TLR1-5, 7-9 ligands for $24 \mathrm{~h}$, and the release of IL-8 was measured. This selection of ligands covered the range of NOD and TLR receptors expressed by these cells as determined by real-time PCR (not shown). As shown in Figure 8, knockdown of MUC1 in gastric cells resulted in significantly increased IL-8 secretion in response to both low and high concentrations of $\gamma$-D-glutamyl-mesodiaminopimelic acid (iE-DAP, NOD1 ligand), polyinosinic: polycytidylic acid (poly I:C, TLR3 ligand), LPS (TLR4 ligand), flagellin (TLR5 ligand), imiquimod (TLR7 ligand), ssRNA40
(TLR8 ligand), and CpG DNA (TLR9 ligand) and to high concentrations of (but not low concentrations) pam3CSK4 (TLR1/2). Conversely, knockdown of MUC13 in both LS513 and LIM2463 cells resulted in significantly decreased production of IL-8 in response to both low and high concentrations of NOD1, TLR3, TLR4, TLR5, and TLR9 ligands and to high concentrations of TLR7 and TLR8 ligands (Figure 8). Production of IL-8 by LS513 cells was generally lower in response to TLR1/2, TLR4, TLR7, TLR8, and TLR9 compared with MKN7 and LIM2463 cells or compared with LS513 cells in response to TNF- $\alpha$ and live pathogens. This suggests that IL- 8 production is dependent on the expression of TLR/NOD receptors and their downstream signaling components in each cell line and the individual stimuli. These results show that MUC1 suppresses IL-8 release, whereas MUC13 promotes IL-8 release following activation of multiple different NOD1 and TLR ligands, which is consistent with modulation of the response to TNF- $\alpha$ and whole pathogens.

\section{MUC1 suppresses, whereas MUC13 promotes NF-kB activation induced by NOD 1 and TLR 3 ligands}

All TLR signaling, either MyD88-dependent or TRIF-dependent, converges on NF-kB, which is a main driver of IL-8 transcription in gastrointestinal epithelial cells. Therefore, to further characterize the mechanism accounting for the differential role of MUC1 and MUC13 in regulating IL-8 production, we examined whether the presence of either MUC1 or MUC13 alters the activation of NF-kB in response to NOD1 and TLR3 (which produced the greatest difference in IL-8 levels when these mucins were knocked down). MKN7 cells were transfected with MUC1 siRNA or both LIM2463 and LS513 cells were transfected with MUC13 siRNA for $48 \mathrm{~h}$, treated with NOD1 or TLR3 ligands, and phosphorylation of NF-kB p65 measured by an AlphaScreen SureFire Assay. Knockdown of MUC1 in MKN7 cells resulted in significantly greater NF- $\kappa B$ p65 phosphorylation compared with cells transfected with the 

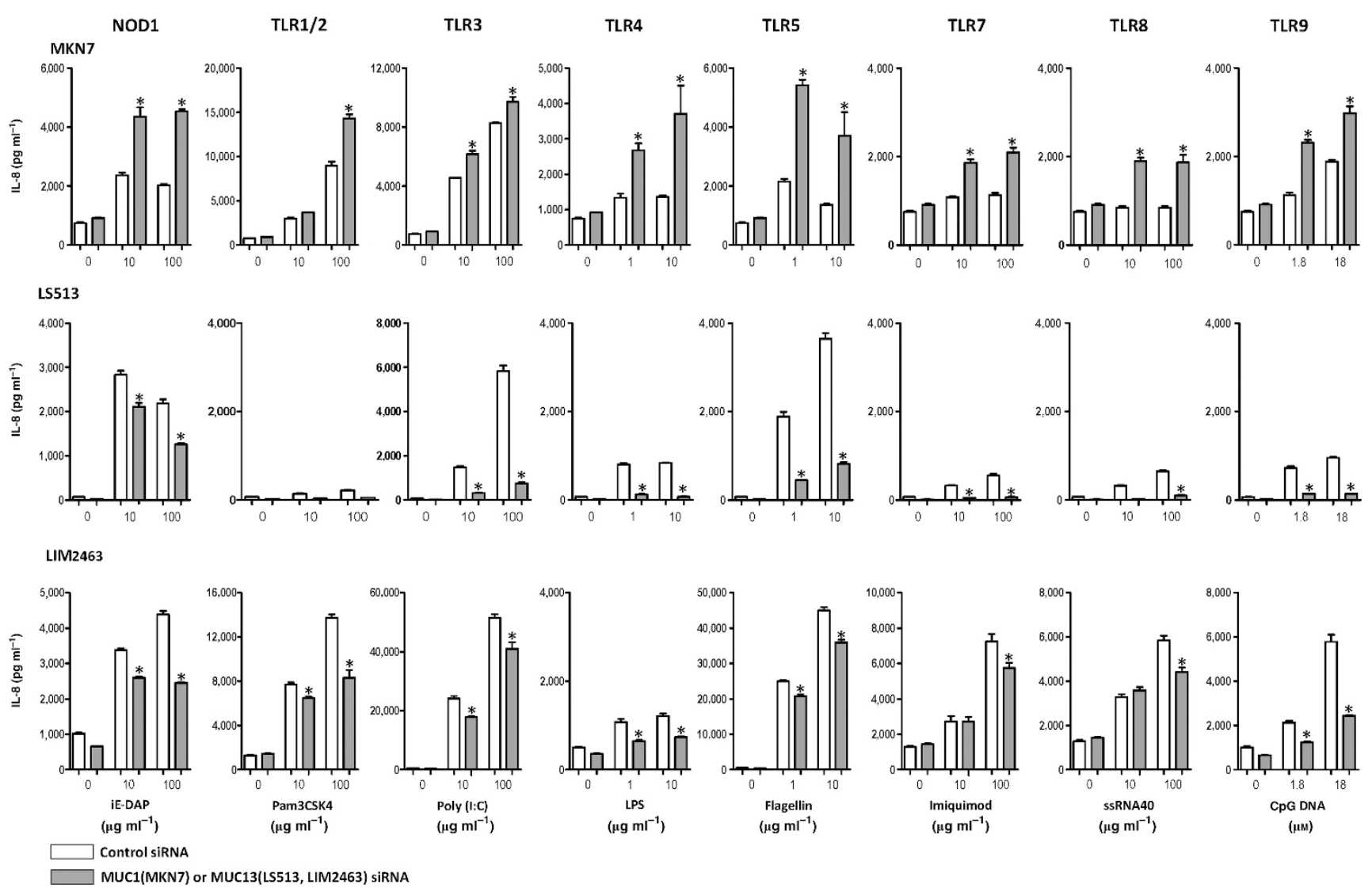

Figure 8 MUC1 inhibits, whereas MUC13 enhances gastrointestinal epithelial cell inflammatory signaling in response to NOD1 (nucleotidebinding oligomerisation domain-containing protein-1) and Toll-like receptor (TLR) ligands. MKN7 cells were transfected with MUC1 or control small interfering RNA (siRNA) and LS513 and LIM2463 cells were transfected with MUC13 or control siRNA for $48 \mathrm{~h}$ and treated with NOD1 or the indicated TLR ligands at the concentrations shown for $24 \mathrm{~h}$ and interleukin (IL)-8 levels in culture media were measured by enzyme-linked immunosorbent assay. Representative of three separate experiments. Statistics: mean \pm s.e.m.; $n \geqslant 4$; Mann-Whitney U-test MUC1 siRNA or MUC13 siRNA vs. control siRNA, ${ }^{*} P<0.05$. CpG DNA, bacterial unmethylated CpG DNA; iE-DAP, $\gamma$-D-glutamyl-meso-diaminopimelic acid; LPS, lipopolysaccharide; poly I:C, polyinosinic:polycytidylic acid.

control siRNA following exposure to NOD1 or TLR3 ligands (Figure 9a). Conversely, LS513 and LIM2463 with MUC13 silencing had significantly less NF- $\mathrm{KB}$ p65 phosphorylation following exposure to NOD1 or TLR3 ligands (Figure 9b). These results are consistent with the earlier demonstrated modulation of NF- $\mathrm{\kappa B}$ activation after exposure to TNF- $\alpha$ and consistent with downstream modulation of multiple pathways leading to NF- $\mathrm{KB}$ activation by the cell surface mucins.

\section{DISCUSSION}

This study demonstrates for the first time that MUC1 and MUC13 cell surface mucins have divergent actions to modulate inflammatory responses induced by TNF- $\alpha$, gastrointestinal pathogens and NOD1 and TLR ligands, with MUC1 being antiinflammatory and MUC13 pro-inflammatory. We have previously shown that MUC1 can act as a releasable decoy molecule on the apical cell surface of mucosal epithelial cells and thereby limit bacterial adherence, infection, and inflammation. ${ }^{3,4,27}$ Our current study shows that multiple members of the cell surface mucin family are important regulators of mucosal epithelial signaling in response to microbes and their products.
Our data demonstrate that MUC1 suppresses NF- $\mathrm{BB}$ activity, which in turn inhibits inflammatory responses of the gastric epithelial cells to TNF- $\alpha$, and that this antiinflammatory activity of MUC1 is also applicable to TLR and NOD1 ligands. These findings are consistent with studies demonstrating that knockdown of MUC1 in AGS gastric cells results in increased nuclear translocation of NF- $\mathrm{\kappa B}$ transcription factors and IL-8 production in response to $H$. pylori treatment ${ }^{21}$ and that $\mathrm{MUC1}$ over expression inhibits activation of TLRs in respiratory epithelial cells. ${ }^{17}$ However, these findings are opposite to findings in MCF-10A and ZR-75-1 breast cancer cells, which suggest that MUC1 is pro-inflammatory via interaction with IKK $\beta$ and IKK $\gamma .{ }^{22,23}$ Although it is difficult to resolve the differences in these studies that could relate to genetic changes in the malignant cells used experimentally or differences between breast and gastrointestinal cells, in our study we found the same influences of MUC1 and MUC13 silencing in human cancer cells and in ex vivo tissue explants fom Mucl and Muc13 knockout mice. In contrast to the effect of MUC1, our data showed, for the first time, that MUC13 promotes NF- $\kappa \mathrm{B}$ activity, enhancing responses of the intestinal epithelial cells to inflammatory and infectious stimuli. In cells 

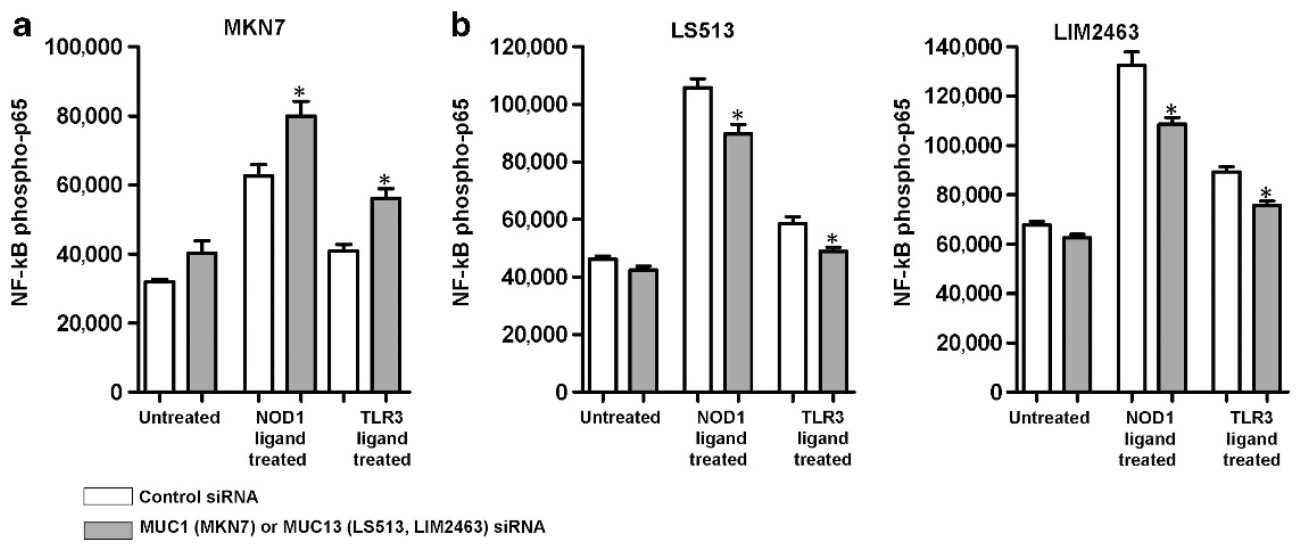

Figure 9 MUC1 suppresses, whereas MUC13 promotes nuclear factor (NF)-KB activation induced by NOD (nucleotide-binding oligomerisation domain) and Toll-like receptor (TLR) ligands. (a) MKN7 cells were transfected with MUC1 or control small interfering RNA (siRNA) for $48 \mathrm{~h}$ and treated with NOD1 (25 $\mathrm{ng} \mathrm{ml}^{-1}$ ) ligand or TLR3 $\left(25 \mathrm{ng} \mathrm{ml}^{-1}\right.$ ) ligand for $24 \mathrm{~h}$. Lysates from untreated or NOD1 ligand- or TLR3 ligand-treated cells were used to measure the phosphorylation of NF-kB p65 Ser536 by AlphaScreen SureFire Assay. (b) LS513 and LIM2463 cells were transfected with MUC13 or control siRNA for $48 \mathrm{~h}$ and treated and assessed as in a. Statistics: mean \pm s.e.m.; $n \geqslant 4$; Mann-Whitney U-test MUC1 siRNA (a) or MUC13 siRNA (b) vs. control siRNA, ${ }^{*} P<0.05$.

where both mucins were expressed, silencing experiments indicated that MUC1 and MUC13 have actively opposing influences on inflammatory signaling.

The main mechanism accounting for the roles of MUC1 or MUC13 in the regulation of IL-8 production in gastrointestinal epithelial cells is through a NF- $\mathrm{KB}$-dependent pathway, as MUC1 inhibited cytokine, NOD1, and TLR ligand-induced NF- $\kappa B$ activity, whereas MUC13 enhanced cytokine, NOD1 and TLR ligand-induced NF- $\kappa B$ activity. Mucin modulation of $\mathrm{NF}-\mathrm{\kappa B}$ signaling was accompanied by increased or decreased phosphorylation and degradation of I $\mathrm{I} B \alpha$ and by increased or decreased translocation of NF- $\kappa B$ p 65 into the nucleus. These observations suggest that MUC1 and MUC13 inhibit or stimulate IL-8 production via a modulator of NF- $\mathrm{\kappa B}$ activation downstream of the TNF and TLR/NOD receptors, probably at the level of the IKK complex, where the cytokine, TLR, and NOD1 signaling pathways converge. For MUC13 in colonic cells, we cannot exclude an effect on additional pathways not involving NF- $\kappa \mathrm{B}$, as the NF- $\kappa \mathrm{B}$ inhibitor could not fully block IL- 8 production in response to TNF- $\alpha$.

We also cannot rule out the possibility that MUC1 and MUC13, at least partially, also work upstream of NF- $\kappa B$ to modulate signaling. Kato et al. ${ }^{28}$ have recently shown that the activation of EGF receptor in respiratory epithelial cells by flagellin phosphorylates MUC1, thus increasing MUC1 association with TLR5 and competitively inhibiting recruitment of MyD88 to TLR5 and subsequent proinflammatory signal transduction. Both MUC1 and MUC13 are localized to subapical granules and the apical membrane,and contain cleavage motifs in the immediate intracellular region of their cytoplasmic domains (CDs) and may be similarly cleaved. However, MUC13 differs from MUC1 in that it has three EGF-like domains in the extracellular domain. ${ }^{29}$ Because of its EGF domains, we considered that MUC13 may interact with EGF receptor in response to inflammatory or infectious stimuli to increase IL-8 production, and it may also influence expression, stabilization, recycling, and activation of the human EGF receptor cascade and its downstream signaling that has major roles in cell proliferation and the regulation of innate immune responses in the intestine, including mucin secretion by goblet cells, and chemokine production by epithelial cells. ${ }^{30}$ Furthermore, Chauhan et al. ${ }^{31}$ have recently shown that MUC13overexpressing human pancreatic cancer cells increase ErbB-2 receptor expression and its phosphorylation at tyrosine 1248 to thereby induce its activation. However, using receptor antibodies to block function, we could find little support for MUC13-modulating inflammatory signaling via either ErbB-1 or ErbB-2.

The different CD structures of MUC1 and MUC13 are likely to be critical to the differences in their modulation of inflammatory responses. The MUC1-CD has been shown to contain multiple binding sites for proteins involved in TNF- $\alpha$ and TLR signaling, such as PI3K, $\beta$-catenin, GSK-3 $\beta$, Shc, Src, and ErbB receptor family, ${ }^{1}$ whereas there is little known about the function of the MUC13-CD. Given that MUC1 and MUC13 are complex, and contain multiple potential phosphorylation motifs, and are regularly internalized into recycling vesicles, it is possible that MUC1 and MUC13 interact with a different repertoire of regulatory proteins in the plasma membrane, cytoplasm, or other intracellular compartments that differentially modulate inflammatory signaling. The extent to which MUC13 has a role in cell signaling remains to be determined. However, by western blotting we have detected phosphorylation of MUC13 consistent with a role in signal transduction and nuclear localization, which is consistent with a role in transcriptional modulation, as is the case for MUC1. ${ }^{32}$

The results from this study provide important insights concerning the anti-inflammatory role of MUC1 vs. the proinflammatory role of MUC13 for understanding how gastrointestinal inflammation might resolve following infection. 
Microbiota and microbial products in the gastrointestinal tract are separated from the epithelium by a viscoelastic mucous gel layer formed by the high molecular mass oligomeric Muc2/ MUC2 mucin glycoproteins. ${ }^{33}$ The microbiota which penetrate this layer, will first "see" the large cell surface mucins such as MUC1, MUC3, MUC4, MUC12 and MUC17, which form the outer glycocalyx due to their extended rigid extracellular domains. Microbiota that get closer to the epithelium will encounter the smaller MUC13, a potentially more dangerous situation for the host. Microbiota and their products fully penetrating this first-line defense, however, encounter both underlying epithelial cells, macrophages, and dendritic cells, where they are recognized in a highly specific manner by a number of prokaryocyte and viral pattern recognition receptors present in these cell types. ${ }^{34}$ It is hypothesized that an encounter with the pattern recognition receptors when MUC13 is also present would elicit inflammation by producing more inflammatory mediators such as IL- 8 and TNF- $\alpha$ to recruit neutrophils into the infected areas than would occur in the absence of this mucin. ${ }^{34}$ Intestinal expression of MUC1 is relatively low before inflammation, and we have shown that intestinal Mucl is upregulated following C. jejuni and C. rodentium infection in mice, ${ }^{3,14}$ and MUC1 expression is also upregulated following TNF- $\alpha$ stimulation in both LIM2463 and LS513 intestinal epithelial cells (Supplementary Figure S1 online). The increased levels of MUC1 in these epithelial cells will likely stereochemically attenuate both penetration of the microbiota and inflammation by dampening activation in response to TNF- $\alpha$ and TLR signaling. Thus, the expression of MUC1 might prevent excessive and prolonged inflammation that would otherwise develop into chronic inflammatory disease. This role for MUC1 in the gut is consistent with the anti-inflammatory role of MUC1 in airway inflammation. ${ }^{17}$

Unlike MUC1, MUC13 is highly expressed by intestinal epithelial cells in resting conditions. It is depleted with acute DSS treatment ${ }^{5}$ and acute C. rodentium infection in mice. ${ }^{14}$ The decreased levels of MUC13 that follow an acute insult could attenuate ongoing inflammation by suppressing further activation of TNF- $\alpha$ TLR signaling. Thus, decreased MUC13, combined with the increased MUC1, may be crucial to the resolution of intestinal inflammation by preventing excessive and prolonged inflammation that would otherwise develop into IBD. Importantly, we have shown that MUC13 was more highly expressed in inflamed colonic mucosal biopsies taken from treatment-naive IBD patients compared to non-inflamed colonic mucosal biopsies taken from healthy or IBD individuals. ${ }^{5}$ Together with the results of the current study, these observations suggest that inappropriate overexpression of MUC13 could lead to aberrant modulation of epithelial cell inflammatory signaling, which in turn could lead to pathological inflammation. Inappropriate MUC1 or MUC13 expression may be responsible, at least in part, for progression from local inflammation to more severe gastrointestinal disease, such as in IBD and cancers; an hypothesis that is consistent with the altered expression profiles of mucins in gastrointestinal inflammatory and malignant diseases. ${ }^{13}$
In summary, our data demonstrate that MUC1 and MUC13 have reciprocal inflammatory actions, which may have an important role in intestinal homeostasis, and that disruption or inappropriate expression of either of these mucins could predispose to infectious and inflammatory disease and inflammation-induced cancer. The results of this study should underpin further exploration of the normal function of members of the cell surface mucin family and their contribution to epithelial infectious and inflammatory diseases.

\section{METHODS}

Reagent. All reagents and chemicals were purchased from SigmaAldrich (St. Louis, MO) unless otherwise stated. Both human and mouse TNF- $\alpha$ was purchased from R\&D Systems (Minneapolis, MN), Bay 11-7085 was purchased from Biomol international (Enzo Life Sciences, Farmingdale, NY), all the TLR and NOD1 ligands were purchased from InvivoGen (San Diego, CA). Anti-EGF receptor (ErbB-1) antibody, cetuximab (Erbitux), and the anti-ErbB-2 antibody, trastuzumab (Herceptin) were obtained from the Mater Health Services Pharmacy (Brisbane, Australia).

Animals and cell culture. All animal experimentation was approved by the University of Queensland Animal Experimentation Ethics Committee. $\mathrm{Mucl}^{-/-}$mice on a $129 / \mathrm{SvJ}$ genetic background ${ }^{35}$ were maintained as a breeding colony, and wild-type $129 / \mathrm{SvJ} \mathrm{Mucl}^{+/+}$ were purchased from Animal Resources Center (Western Australia, Australia). Mice were sex and age matched within experiments (6-12 weeks of age). Muc13 ${ }^{-1-}$ mice were on a C57BL6 $\times 129 / \mathrm{SvJ}$ background and littermate $M u c 13^{-1-}$ and wild-type $M u c 13^{+/+}$ mice for experiments were generated by crossing heterozygous mice as previously described. ${ }^{5}$ The stomach and intestinal explants from $\mathrm{Mucl}^{-/-}$and $\mathrm{Mucl}^{+/+}$mice and intestinal explants from $\mathrm{Muc13} 3^{-/-}$ and $\mathrm{Mucl3}^{+/+}$mice were maintained in RPMI-1640 (Life Technologies, Carlsbad, CA) with $10 \%$ heat-inactivated fetal calf serum, $200 \mathrm{U} \mathrm{ml}^{-1}$ penicillin, $200 \mu \mathrm{g} \mathrm{ml}^{-1}$ streptomycin, and $2 \mathrm{mM} \mathrm{L-glu-}$ tamine up to $24 \mathrm{~h}$. Human MKN7 gastric, LS513 and LIM2463 intestinal epithelial cells were propagated in RPM1-1640 (Life Technologies) with $10 \%$ heat-inactivated fetal calf serum, $100 \mathrm{U} \mathrm{ml}^{-1}$ penicillin, $100 \mu \mathrm{g} \mathrm{ml}^{-1}$ streptomycin, and $2 \mathrm{~mm}$ L-glutamine.

SiRNA transfection. siRNA specific for MUC1 and MUC13 as well as non-targeted control siRNA were chemically synthesized (Dharmacon Research, Lafayette, CO) as previously described. ${ }^{5,27}$ MKN7 cells with a confluence of $70-80 \%$ were transfected with either $100 \mathrm{nM}$ of $M U C 1$ siRNA or control siRNA using Lipofectamine 2000 Reagent (Life Technologies) according to the manufacturer's instructions. LIM2463 or LS513 cells with a confluence of 70-80\% were transfected with either $100 \mathrm{~nm}$ of MUC13 siRNA or control siRNA using Lipofectamine 2000 Reagent (Life Technologies) according to the manufacturer's instructions. Forty-eight hours after transfection when cultures were fully confluent, the cells were treated with either TNF- $\alpha$, NOD1 or TLR ligands for times indicated in the Figure legends. The level of knockdown of MUC1 protein was measured using flow cytometry (see below), whereas in the absence of an extracellular domain antibody for flow cytometry, MUC13 protein was detected by western blotting (antibody clone H-300 from Santa Cruz Biotechnology, Santa Cruz, CA). The blot was simultaneously stained with antibodies reactive with $\beta$-actin as a loading control and detection using chemiluminescence or dual-label infra-red conjugates on an Odyssey instrument (LI-COR Biosciences, Lincoln, NE).

Flow cytometry. MKN7 cells were harvested with trypsin and incubated with the anti-MUC1 antibody BC2 (against the extracellular domain of MUC1) or isotype control 401.21 at $3 \mu \mathrm{g} \mathrm{ml}{ }^{-1}$ in $1 \%$ bovine serum albumin in phosphate-buffered saline for $60 \mathrm{~min}$ at $4{ }^{\circ} \mathrm{C}$ and then with anti-mouse antibody conjugated to Alexa fluor 488 (Life 
Technologies, Carlsbad, CA). After staining, all cells were fixed with $1 \%$ paraformaldehyde. The analysis was gated to exclude dead cells and assessment of staining was performed on a LSRII Flow Cytometer (BD Biosciences, San Jose, CA) using the Diva software (BD Biosciences).

AlphaScreen SureFire NF- $\kappa$ Bp65 Assay. All reagents were supplied in the AlphaScreen SureFire NF- $\mathrm{kBp} 65$ (p-Ser536) assay kit (Perkin Elmer, Waltham, MA). The assay was performed in 384-well white proxiplates according to the manufacturer's instructions. Briefly, cells were harvested and lysed in the AlphaScreen SureFire lysis buffer contained in the kit and freshly added protease inhibitor cocktail (Roche, Mannheim, Germany) and Phosphostop (Roche). The amount of proteins in the lysate was measured using BCA Protein Assay Kit (Thermo Scientific, Waltham, MA) with bovine serum albumin as a standard. The detection mix was added to the aliquots of the lysate containing $5 \mu \mathrm{g}$ of total protein. The detection mix consisted of Reaction Buffer, Dilution Buffer, Activation Buffer, Acceptor Beads, and Donor Beads (prepared in a 40:20:10:1:1 ratio) prepared under low light conditions. The plate was incubated overnight at room temperature in the dark. Plates were read on a FLUOstar Omega instrument (BMG LabTech, Ortenberg, Germany).

Immunoblot analyses. Sub-confluent cells were collected, washed with phosphate-buffered saline, $\mathrm{pH} \mathrm{7.4}$, at $4{ }^{\circ} \mathrm{C}$ and then treated for $45 \mathrm{~min}$ on ice with RIPA cell lysate buffer (RIPA buffer: $50 \mathrm{~mm}$ TrisHCI, pH 7.5, $150 \mathrm{~mm} \mathrm{NaCI}, 1.0 \%$ Nonidet P-40, $0.1 \%$ sodium deoxycholate, and $1.0 \%$ protease inhibitor cocktail) while rocking every $10 \mathrm{~min}$. The resulting lysates were centrifuged at $16,000 \mathrm{~g}$ for $20 \mathrm{~min}$ at $4{ }^{\circ} \mathrm{C}$ to remove cell debris.

Nuclear and cytosolic fractions were prepared with using NE-PER nuclear and cytoplasmic extraction Kit (Thermo Scientific, Rockford, IL) following the manufacturer's instructions. Protein concentrations were measured using the BCA Protein Assay Kit (Thermo Scientific, Waltham, MA) with bovine serum albumin as a standard. Aliquots of the lysate containing $30 \mu \mathrm{g}$ of total protein were resuspended in SDSPAGE (sodium dodecyl sulfate-polyacrylamide gel electrophoresis) Laemmli buffer $(0.05 \mathrm{~m}$ Tris-HCI, pH 6.8, 2.55 2-mercaptoethanol, $1.0 \%$ SDS, $5 \%$ glycerol, and $0.15 \%$ bromophenol blue), boiled for $5 \mathrm{~min}$, and resolved on $4-12 \%$ acrylamide gels. Resolved proteins were transferred to polyvinylidene difluoride membranes, probed with anti$\beta$-actin (Novus Biologicals, Littleton, CO), anti-NF-кBp65 (Cell Signaling Technology, MA), anti-total $\mathrm{I} \kappa \mathrm{B} \alpha$ (Cell Signaling Technology), anti-phospho-IкB $\alpha$ (Cell Signaling Technology), anti-phosphotyrosine mouse mAb (Cell Signaling Technology), or anti-lamin B (Abcam, Cambridge, UK). Detection was by chemiluminescence or dual-label infra-red analysis as above.

Analysis of secreted MIP-2 $\alpha$ or IL-8 by ELISA. Mouse MIP- $2 \alpha$ production by cultured explants in conditioned medium was quantified by ELISA (R\&D Systems) following the manufacturer's instructions. The concentration of secreted human IL- 8 by MKN7, LS513, and LIM2463 cells was determined by ELISA (BD Biosciences) following the manufacturer's instructions.

H. pylori and C. jejuni cultures. H. pylori $J 99$ strain was grown on Brucella agar supplemented with $10 \%$ bovine blood, $2 \%$ Vitox (Oxoid, Basingstoke, UK), $10 \mathrm{mg} \mathrm{ml}^{-1}$ vancomycin (Sigma-Aldrich), $5 \mathrm{mg} \mathrm{ml}^{-1}$ trimethoprim (Sigma-Aldrich) and $4 \mathrm{mg} \mathrm{ml}^{-1}$ amphoteracin $\mathrm{B}$ (Sigma-Aldrich) for 4 days in $5 \% \mathrm{O}_{2}$ and $15 \% \mathrm{CO}_{2}$ at $37^{\circ} \mathrm{C}$. C. jejuni strain $81-126$ was grown on solid selective agar (2\% Columbia agar, $1 \%$ bacteriological agar, $5 \%$ defibrinated horse blood, Skirrow Selective Supplement; Oxoid) under microaerophilic conditions (5\% $\mathrm{O}_{2}, 15 \% \mathrm{CO}_{2}, 80 \% \mathrm{~N}_{2}$; BOC Gases, North Ryde, NSW, Australia) at $42{ }^{\circ} \mathrm{C}$ for $48 \mathrm{~h}$. The co-culture experiments were performed on confluent MKN7 cells with $H$. pylori and confluent LS513 cells with $C$. jejuni, respectively. The cells were transferred to microaerophilic conditions at the start of the co-culture.
SUPPLEMENTARY MATERIAL is linked to the online version of the paper at http://www.nature.com/mi

\section{ACKNOWLEDGEMENTS}

Supported by NHMRC project grant 543704 and the Victorian Government's Operational Infrastructure Support Program. MAM and PS are supported by NHMRC Senior Research Fellowships, and THF by a NHMRC Practitioner Fellowship. We thank Hui Tong and Martina Proctor for technical assistance.

\section{DISCLOSURE}

The authors declared no conflict of interest.

c 2013 Society for Mucosal Immunology

\section{REFERENCES}

1. McGuckin, M.A., Linden, S.K., Sutton, P. \& Florin, T.H. Mucin dynamics and enteric pathogens. Nat. Rev. Microbiol. 9, 265-278 (2011).

2. Petersson, J. et al. Importance and regulation of the colonic mucus barrier in a mouse model of colitis. Am. J. Physiol. Gastrointest. Liver Physio/ 300, G327-G333 (2011).

3. McAuley, J.L. et al. MUC1 cell surface mucin is a critical element of the mucosal barrier to infection. J. Clin. Invest 117, 2313-2324 (2007).

4. McGuckin, M.A. et al. Muc1 mucin limits both Helicobacter pylori colonization of the murine gastric mucosa and associated gastritis. Gastroenterology 133, 1210-1218 (2007).

5. Sheng, Y.H. et al. The MUC13 cell-surface mucin protects against intestinal inflammation by inhibiting epithelial cell apoptosis. Gut 60, 1661-1670 (2011)

6. Fontaine, O. et al. Setting research priorities to reduce global mortality from childhood diarrhoea by 2015. PLoS Med. 6, e412009).

7. Franke, A. e.a. Meta-analysis increases to 71 the tally of confirmed Crohn's disease susceptibility loci. Nat. Genet. 42, 1118-1125 (2010).

8. Moehle, C. et al. Aberrant intestinal expression and allelic variants of mucin genes associated with inflammatory bowel disease. J. Mol. Med 84, 1055-1066 (2006).

9. Peleteiro, B., Lunet, N., Santos-Silva, F., David, L., Figueiredo, C. \& Barros, $H$. Short mucin 1 alleles are associated with low virulent $H$. pylori strains infection. World J. Gastroenterol. 13, 1885-1886 (2007).

10. Vinall, L.E. et al. Altered expression and allelic association of the hypervariable membrane mucin MUC1 in Helicobacter pylori gastritis. Gastroenterology 123, 41-49 (2002).

11. Huang, X. et al. Polymorphisms of three gene-derived STS on pig chromosome $13 q 41$ are associated with susceptibility to enterotoxigenic Escherichia coli F4ab/ac in pigs. Sci. China C. Life. Sci 51, 614-619 (2008).

12. Packer, L.M., Williams, S.J., Callaghan, S., Gotley, D.C. \& McGuckin, M.A. Expression of the cell surface mucin gene family in adenocarcinomas. Int. J. Oncol. 25, 1119-1126 (2004).

13. Sheng, Y.H., Hasnain, S.Z., Florin, T.H. \& McGuckin, M.A Mucins in inflammatory bowel diseases and colorectal cancer. J. Gastroenterol. Hepatol. 27, 28-38 (2012).

14. Linden, S.K., Florin, T.H. \& McGuckin, M.A. Mucin dynamics in intestinal bacterial infection. PLoS One. 3, e3952 (2008).

15. Longman, R.J., Poulsom, R., Corfield, A.P., Warren, B.F., Wright, N.A. \& Thomas, M.G. Alterations in the composition of the supramucosal defense barrier in relation to disease severity of ulcerative colitis. J. Histochem. Cytochem. 54, 1335-1348 (2006).

16. Tsai, C.J. et al. Changes of gene expression in gastric preneoplasia following Helicobacter pylori eradication therapy. Cancer Epidemiol Biomarkers Prev 15, 272-280 (2006).

17. Ueno, K. et al. MUC1 mucin is a negative regulator of Toll-like receptor signaling. Am. J. Respir. Cell. Mol. Biol 38, 263-268 (2008).

18. Litvinov, S.V. \& Hilkens, J. The epithelial sialomucin, episialin, is sialylated during recycling. J. Biol. Chem. 268, 21364-21371 (1993).

19. Lillehoj, E.P., Kim, H., Chun, E.Y. \& Kim, K.C. Pseudomonas aeruginosa stimulates phosphorylation of the airway epithelial membrane glycoprotein Muc1 and activates MAP kinase. Am. J. Physiol. Lung Cell. Mol. Physiol 287, L809-L815 (2004).

20. Kato, K., Lu, W., Kai, H. \& Kim, K.C. Phosphoinositide 3-kinase is activated by MUC1 but not responsible for MUC1-induced suppression of Toll-like 


\section{ARTICLES}

receptor 5 signaling. Am. J. Physiol. Lung Cell. Mol. Physiol 293, L686-L692 (2007).

21. Guang, W., Ding, H., Czinn, S.J., Kim, K.C., Blanchard, T.G. \& Lillehoj, E.P. Muc1 cell surface mucin attenuates epithelial inflammation in response to a common mucosal pathogen. J. Biol. Chem. 285, 20547-20557 (2010).

22. Ahmad, R. et al. MUC1 oncoprotein activates the lkappaB kinase beta complex and constitutive NF-kappaB signalling. Nat. Cell. Biol 9, 1419-1427 (2007).

23. Ahmad, R. et al. MUC1-C oncoprotein functions as a direct activator of the nuclear factor-kappaB p65 transcription factor. Cancer Res 69 7013-7021 (2009).

24. Remick, D.G., Green, L.B., Newcomb, D.E., Garg, S.J., Bolgos, G.L. \& Call, D.R. CXC chemokine redundancy ensures local neutrophil recruitment during acute inflammation. Am. J. Pathol. 159, 1149-1157 (2001).

25. Revishvili, A., Umarov, V.M. \& Kadyrev, O.M. The clinical evaluation of different regimens of physiological electrocardiostimulation. Grud. Serdechnososudistaia Khir. 6, 14-17 (1993).

26. Hacker, H. \& Karin, M. Regulation and function of IKK and IKK-related kinases. Sci STKE 2006, 13 (2006).

27. Linden, S.K. et al. MUC1 limits Helicobacter pylori infection both by steric hindrance and by acting as a releasable decoy. PLoS Pathog 5, e1000617 (2009).

28. Kato, K. et al. Membrane-tethered MUC1 mucin is phosphorylated by epidermal growth factor receptor in airway epithelial cells and associates with TLR5 to inhibit recruitment of MyD88. J. Immunol 188, 2014-2022 (2012).

29. Williams, S.J., Wreschner, D.H., Tran, M., Eyre, H.J., Sutherland, G.R. \& McGuckin, M.A. Muc13, a novel human cell surface mucin expressed by epithelial and hemopoietic cells. J. Biol. Chem. 276, 18327-18336 (2001).

30. Burgel, P.R. \& Nadel, J.A. Epidermal growth factor receptor-mediated innate immune responses and their roles in airway diseases. Eur. Respir. J 32, 1068-1081 (2008).

31. Chauhan, S.C. et al. MUC13 Mucin Augments Pancreatic Tumorigenesis. Mol. Cancer Ther 11, 24-33 (2012).

32. Wen, Y., Caffrey, T.C., Wheelock, M.J., Johnson, K.R. \& Hollingsworth, M.A. Nuclear association of the cytoplasmic tail of $\mathrm{MUC1}$ and beta-catenin. J. Biol. Chem. 278, 38029-38039 (2003).

33. Johansson, M.E., Phillipson, M., Petersson, J., Velcich, A., Holm, L. \& Hansson, G.C. The inner of the two Muc2 mucin-dependent mucus layers in colon is devoid of bacteria. Proc. Natl. Acad. Sci. USA 105, 15064-15069 (2008).

34. Abreu, M.T. Toll-like receptor signalling in the intestinal epithelium: how bacterial recognition shapes intestinal function. Nat. Rev. Immunol 10, 131-144 (2010).

35. Spicer, A.P., Rowse, G.J., Lidner, T.K. \& Gendler, S.J. Delayed mammary tumor progression in Muc-1 null mice. J. Biol. Chem. 270, 30093-30101 (1995). 